\title{
Influence of virgin coconut oil (VCNO) on oxidative stress, serum testosterone and gonadotropic hormones (FSH, LH) in chronic ethanol ingestion.
}

\author{
Dosumu, O. O., Duru, F. I. O., Osinubi, A. A., Oremosu, A. A., Noronha, C. C. \\ Department of Anatomy, Faculty of Basic Medical Sciences, College of Medicine, \\ University of Lagos, Idi-araba, Lagos, Nigeria
}

\begin{abstract}
The present study explored the effect of virgin coconut oil on oxidative stress, testosterone and gonadotropic hormones in alcohol-induced testicular injury. Twenty-five male rats were randomly assigned to one of five groups $(n=5)$. The oil was processed from the mature endosperm of coconut and administered at $6.7 \mathrm{ml} / \mathrm{kg}$ body weight, while alcohol was given orally at $7 \mathrm{ml} / \mathrm{kg}$ body weight. After sacrifice, testicular malondialdehyde and serum hormone levels were determined. Testicular malondialdehyde levels increased significantly in animals treated with alcohol alone $(p<0.001)$, and animals treated with alcohol following virgin coconut oil treatment $(p<0.05)$ while the other groups showed a significant decrease $(p<0.05)$ when compared with the control. However, when compared with the group treated with alcohol alone, all the other groups showed a significant decrease $(p<0.05)$ in testicular malondialdehyde level. Serum testosterone levels increased significantly $(p<0.05)$ in rats treated with virgin coconut oil when compared with the alcohol-only treated group, while serum FSH and $\mathrm{LH}$ levels were not significantly different from the control values in all the treatment groups. Virgin coconut oil effectively lowered alcohol-induced oxidative stress by reducing testicular malondialdehyde levels and ameliorated the deleterious effect of alcohol on serum testosterone level, but showed no effect on serum FSH and LH levels.
\end{abstract}

Keywords: Virgin coconut oil, testes, testosterone, gonadotropic hormones

\section{INTRODUCTION}

Acute and chronic alcohol misuse or abuse has been shown to cause derangements in reproductive function in humans and experimental animals (Mendelson et al., 1981; 1987; Little et al., 1992). The male reproductive endocrine pathway consists of three parts, hypothalamus, anterior pituitary and the testes and is controlled through a classic negative feedback mechanism (Emanuele \& Emanuele, 1998). Chronic ethanol consumption reportedly impacts all levels of the male hypothalamic-pituitary-gonadal axis (Van Thiel, 1983; Emanuele \& Emanuele, 2001). It also caused sexual dysfunction and impaired sperm production in humans and in animal models (Van Thiel \& Lester, 1979).

Studies have shown that excessive ethanol ingestion induces hypoandrogenism and hypogonadism in males with low testosterone levels (Iturriaga et al., 1995; Ren et al., 2005). In fact, research with animals has consistently demonstrated an association between both acute and chronic alcohol consumption and low testosterone levels (Little et al., 1992; Emanuele \& Emanuele, 2001).

The oxidation of alcohol, a process that occurs as part of alcohol metabolism generates by-products called oxidants that can contribute to cell damage and may play a role in alcohol-induced damage in the testes (Bai \& Cederbaum, 2006). Increased oxidative stress is a well-accepted mechanism of alcoholinduced tissue injury in the liver, heart and CNS (Aleynik et al., 1998; Polavarapu et al., 1998) and it has also been reported to occur in the testes (Emanuele et al., 2001). Alcohol consumption may induce oxidative damage either by enhancing the production of toxic compounds called free radicals or by decreasing the levels of antioxidants (Battino et al., 1999; Dey \& Cederbaum, 2006; Lu \& Cederbaum, 2008).

Coconut oil has been widely used throughout history for its medicinal value and has served man as important food for thousands of years (Ghazali et al., 2009). It consists of a mixture of triglycerides 
containing only short and medium chain saturated fatty acids (92\%) and unsaturated fatty acids (8\%) (Reynolds, 1982; Dayrit, 2003; Che Mann \& Marina, 2006).

The potential benefits of VCNO in preventing or ameliorating different biological conditions due to its active polyphenol components has been demonstrated (Nevin \& Rajamohan, 2004). The extraction of VCNO from the fresh endosperm of coconut is believed to be more beneficial than usually prepared copra oil because its mode of extraction retains more biologically active components such as vitamin $\mathrm{E}$ and polyphenols (Nevin \& Rajamohan, 2004). A recent study conducted by De Lourdes et al. (2007) showed that despite increased testosterone levels, CNO decreased the risk of prostatic cancer by significantly reducing increase in prostate: body weight ratio induced by testosterone. Though research has reported the use of CNO in a number of biological conditions, there is a dearth of literature on its use as a pro-fertility agent. This has prompted the present investigation.

\section{MATERIALS AND METHODS}

Animal experiments: Five groups of SpragueDawley rats weighing between 100-150 g were used for the study. The animals were housed with 12:12 light-dark cycle at $27 \pm 1^{\circ} \mathrm{C}$ in the animal house of the department of anatomy, University of Lagos. The experimental groups were divided into: Group I (control); Group II (alcohol alone); Group III (alcohol + VCNO); Group IV (alcohol 8 weeks / VCNO 8 weeks); Group V (VCNO 8 weeks / alcohol 8 weeks). VCNO was given at $6.7 \mathrm{ml} / \mathrm{kg}$ body weight per day while alcohol was administered at $7 \mathrm{ml} / \mathrm{kg}$ body weight per day following a modification of the protocols described by Dayrit, (2000) and ElAshmawy et al. (2007) respectively. Both treatments were given by gavage using a metal oropharyngeal cannula as described in the protocols used by Akinola et al. (2007) thrice in a week. Control animals received normal saline throughout the duration of the experiment. After 8 weeks treatment period, the animals were sacrificed by cervical dislocation and blood was obtained by ventricular puncture for hormonal assay. The testes were dissected out, trimmed of fat and used for the various assays.

Materials used: Alcohol: $30 \%$ ethanol prepared from absolute ethanol $(99.86 \% \mathrm{v} / \mathrm{v})$ with substance identification number 1170 manufactured by James Burrough (F.A.D Ltd. UK) was used for the study.
Virgin coconut oil: The solid endosperm of mature coconuts harvested between the months of December-April (2009) and authenticated as Cocos nucifera palmae at the Federal Institute of Forestry Research Ibadan (Voucher number, 107825) were used for the study.

The VCNO was extracted using a modified wet extraction method described by Nevin and Rajamohan, (2004, 2006). The solid endosperm of mature coconut was crushed and made into a viscous slurry. About $500 \mathrm{ml}$ of water was added to the slurry obtained and squeezed through a fine sieve to obtain coconut milk. The resultant coconut milk was left for about 24 hours to facilitate the gravitational separation of the emulsion as previously described by Onsaard et al., (2005) and Nour et al., (2009). Demulsification produced layers of an aqueous phase (water) on the bottom, an emulsion phase (cream) in the middle layer and an oil phase on top as described by Nour et al. (2009). The oil on top was scooped and heated for about 5 minutes to remove moisture. The obtained VCNO was then filtered through a fine sieve, stored at room temperature and used for the experiment.

\section{Biochemical Investigation}

Determination of testicular malondialdehyde levels: Lipid peroxidation as evidenced by the formation of thiobarbituric acid reactive substances (TBARS) was measured using the method described by Niehaus and Samuelsson, (1968). A $0.1 \mathrm{ml}$ tissue homogenate (Tris-Hcl buffer, $\mathrm{pH}$ 7.5) was treated with $2 \mathrm{ml}$ of (1:1:1 ratio) TBA-TCA-HCL reagent (Thiobarbituric acid $0.37 \%, 0.25 \mathrm{~N}$ Hydrochloric acid, and 15\% Trichloroacetic acid [TCA]) and placed in water bath for 15 minutes. Subsequently, the samples were cooled and centrifuged at room temperature for 10 minutes at $1000 \mathrm{rpm}$. The absorbance of clear supernatant was measured against reference blank at $535 \mathrm{~nm}$. Concentration was calculated using the molar absorptivity of malondialdehyde, which is $1.56 \times 10^{5} \mathrm{M}^{-1} \mathrm{~cm}^{-1}$.

Hormone determination: The serum levels of testosterone, $\mathrm{FSH}$ and $\mathrm{LH}$ were measured using commercially available enzyme-linked immunoassay kit (Diagnostic automation Inc, CA) according to the manufacturer's instructions.

Statistical analysis: Statistical analysis was done using student's $t$ test and analysis of variance (ANOVA) with Bonferroni's post hoc test. Data was 
expressed as means \pm SD and $p<0.05$ was considered to be significant.

\section{RESULTS}

Testicular malondialdehyde level: tMDA levels increased significantly in animals treated with alcohol alone [Group II] $(p<0.001)$, and animals treated with alcohol following VCNO treatment [Group V] $(p<$ 0.05 ) while groups Groups III \& IV showed a significant decrease $(p<0.05)$ when compared with the control. However when compared with the group treated with alcohol alone, all the other groups showed a significant decrease $(p<0.05)$ in tMDA levels (Table I).

Table 1: Effect of the administration of VCNO and alcohol on testicular malondialdehyde levels after eight week-treatment regime.

\begin{tabular}{|l|l|}
\hline Treatment Groups & tMDA (nmol/min) \\
\hline I (Control) & $10.68 \pm 1.04$ \\
\hline II (ALC 8 WKS) & $29.24 \pm 2.51^{\mathrm{a}}$ \\
\hline III (ALC + VCNO 8 WKS) & $8.45 \pm 1.07^{\mathrm{b}}$ \\
\hline $\begin{array}{l}\text { IV (ALC 8 WKS / VCNO 8 } \\
\text { WKS) }\end{array}$ & $6.62 \pm 0.70^{\mathrm{b}}$ \\
\hline $\begin{array}{l}\text { V (VCNO 8 WKS / ALC 8 } \\
\text { WKS) }\end{array}$ & $18.01 \pm 2.45^{\mathrm{b}}$ \\
\hline
\end{tabular}

Key

b: Significance at $p<0.05$

a: Significance at $p<0.001$

Serum hormone levels: When compared with the control group, the alcohol-alone treated group showed a significant reduction in testosterone levels $(p<0.05)$, while groups III and IV that received alcohol together with VCNO and VCNO following alcohol treatment respectively showed a significant increase $(p<0.05)$. Group $V$ that received alcohol following $\mathrm{CNO}$ treatment showed no significant difference from the value of control. However, when these groups were compared with the groups treated with alcohol alone, they showed a significant increase in testosterone levels $(p<0.05)$ (Figure 1$)$.
When all the treated groups were compared with the control as well as with the alcohol-only treated group, both $\mathrm{FSH}$ and $\mathrm{LH}$ levels were not significantly different (Figure 1).

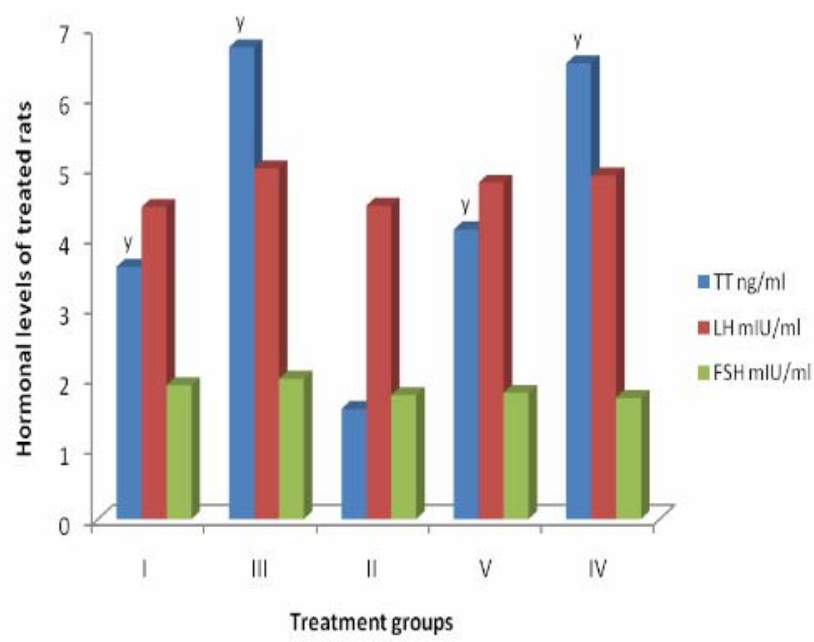

Fig 1: Effect of VCNO and alcohol treatment on serum TT, LH and FSH concentration in Sprague-Dawley rats after 8 week-treatment regime.

$\mathrm{y}: p<0.05$ significant from values of II

Key

Group I - Control

Group III- ALC + CNO 8 WEEKS

Group II- ALC 8 WEEKS

Group V- CNO 8 WEEKS / ALC 8 WEEKS

Group IV- ALC 8 WEEKS / CNO 8 WEEKS

\section{DISCUSSION}

The effects of alcohol on testosterone and gonadotropic hormones have been reported by different authors. While Frias et al. (2000) reported that alcohol ingestion produced a decrease in plasma testosterone levels and no significant changes in either FSH or LH levels; Little et al. (1992) demonstrated that administration of alcohol to prepubescent males stimulated testosterone secretion with no changes in serum LH. Furthermore, they stated that when alcohol was administered to 
adult male rats, both testosterone and $\mathrm{LH}$ levels decreased.

In the studies of Ren et al. (2005) chronic exposure of pubertal male rats to ethanol resulted in a decline in serum testosterone level accompanied by a decrease or "inappropriately" normal serum LH and FSH levels, suggesting impaired secretory release of gonadotropins. The present study agrees with these findings as alcohol decreased serum testosterone levels in the alcohol-only treated groups and showed no significant changes in $\mathrm{FSH}$ and $\mathrm{LH}$ values in all the rats.

Different authors have pointed out that although the liver is the primary site for the breakdown of alcohol, the testes also possesses the necessary enzymes. In the presence of alcohol, these enzymes rather than facilitate testosterone production are diverted to alcohol breakdown, thus leading to a reduction in testosterone levels over time (Ellingboe \& Varanelli, 1979; Chiao et al., 2008). Studies have also shown that alcohol consumption resulted in elevated levels of the stress hormone, cortisol. Cortisol acts directly on cells in the testes to inhibit the production and release of testosterone, leading to suppressed testosterone levels (Valmaki et al., 1984; Venkat et al., 2009). These reasons could account for the suppressed testosterone levels observed in the alcohol-only treated groups.

While alcohol suppressed testosterone production in the alcohol-only treated groups (group II), all the groups treated with VCNO showed a significant increase in serum testosterone levels when compared with group II. This study agrees with the findings of other authors who have reported that animals fed CNO diets showed high testicular levels of antioxidants in addition to significantly high levels of testosterone and increase in the activities of 3-beta or 17-beta dehydroxysteroid dehydrogenase enzymes, key enzymes involved in testosterone biosynthesis (Hurtado de Catalfo et al., 2008, 2009).

In the present investigation, tMDA levels were elevated in the alcohol-only treated group, suggestion a state of oxidative stress in the testes. However, the administration of VCNO with alcohol ameliorated these effects. Hence, this could also account for the significant increase in testosterone levels observed in the groups treated with VCNO when compared with the alcohol-only treated groups. The studies of Maneesh et al. (2006), have suggested that increased oxidative stress caused damage to testosterone secreting Leydig cells and supporting Sertoli cells as well as impairing the HPG axis. In addition, Calvin et al. (1981) suggested that the metabolic pathway of testosterone synthesis requires protection against peroxidation and will be affected by a decrease in the activity of antioxidants. It is therefore logical to believe that substances that could ameliorate these effects will also boost testosterone synthesis and release.

It is possible that the biologically active components in VCNO such as tocotrienols (which have been reported as having more potent antioxidant properties than even alpha-tocopherol [Serbinova et al., 1991; Serbinova \& Packer, 1994]), flavonoids and other polyphenols are responsible for the antioxidant properties observed in this oil. Phenolics in particular have been recognised as a powerful counter measure against lipid peroxidation (Schroeter et al., 2000; Ramos et al., 2005). Phenolic compounds can act as free radical scavengers by virtue of their hydrogen donating ability, forming aryloxyl radicals (Dinkova-Kostova \& Talalay, 1999). In addition, phenolics have also been found interacting with the oxidative cascade preventing its outcome (Unnikishnan \& Rao, 1992), quenching oxygen and making it less available for oxidative reaction (Soudamini et al., 1992). These antioxidant properties demonstrated by VCNO may account for its ability to decrease oxidative stress and prevent tissue damage in the testes as well as protect the metabolic pathway of testosterone against peroxidation thereby preventing the suppression of testosterone as observed in the alcohol-only treated group.

Several mechanisms can account for the "inappropriately" unchanged serum $\mathrm{LH}$ and FSH levels observed in the present study and protein retention has been sighted as one of them (Salonen \& Huhtaniem, 1990). Research on the liver has demonstrated that short and long-term ethanol exposure induces retention of nascent proteins (Larkin et al., 1996). The ethanol-induced protein retention in the liver resulted from impaired vesicle transport and protein trafficking (Ghosh et al., 1995; Torok et al., 1997).

Studies have shown that Rab proteins, a group of small GTP proteins are important regulators of transport of vesicles between the intracellular organelles (Novick \& Zerial, 1997; Segev, 2001; Takai et al., 2001). When glycoproteins such as FSH and $\mathrm{LH}$ move along the secretory pathway from the 
endoplasmic reticulum to plasma membrane, they are contained in membrane limited vesicles (Baenziger \& Green, 1988). Reductions in these key Rab proteins may lead to altered trafficking and may play a role in disruption of pituitary FSH and $\mathrm{LH}$ secretion. Studies of Ren et al. (2005) have shown that ethanol decreases Rab protein levels in the pituitary of treated rats. In agreement with these findings, Tisdale et al. (1992) have reported that Rab protein mutations inhibit vesicular transport, resulting in protein accumulation.

Hence, chronic ethanol administration may affect pituitary Rab proteins and disrupt the vesiclemediated secretory processes. Thus impaired synthesis or secretion of $\mathrm{LH}$ and $\mathrm{FSH}$ could result, explaining the inappropriately normal serum gonadotropin levels observed in the study. It is premature to conclude whether or not VCNO had any effect on the gonadotropic hormones since the duration of endocrinological recovery after alcohol ingestion is a long-lasting process requiring different times for different hormones to recover, during which the normal glandular-pituitary feed-back process may be partly put out of order (Ruusa et al., 1997).

Conclusion: In conclusion, we report that VCNO effectively lowered alcohol-induced oxidative stress by reducing tMDA levels and ameliorated the deleterious effect of alcohol on serum testosterone level, but showed no effect on serum FSH and LH levels.

\section{REFERENCES}

Akinola, O. B., Dosumu, O. O., Akinleye, S. O. (2007). Effect of cottonseed oil and Aloe vera supplement on the sperm parameters of male wistar rats. The Journal of Health Sciences, 14(2): 38-41.

Aleynik, S. I., Leo, M. A., Aleysink, M. K., Lieber, C. S. (1998). Increasing circulating products of lipid peroxidation in patients with alcoholic liver disease. Alcoholism: Clinical and Experimental Research, 22: 192-196.

Baenziger, J. U., Green, E. D. (1988). Pituitary glycoprotein hormone oligosaccharides: structure, synthesis and function of the asparagine-linked oligosaccharides on lutropin, follitropin and thyrotropin. Biochimica et Biophysica Acta, 947: 287-306.

Bai, J., Cederbaum, A. I. (2006). Overexpression of CYPSE1 in mitochondria sensitizes HepG2 cells to the toxicity caused by depletion of glutathione. Journal of Biological Chemistry, 281: 5128-5136.
Battino, M., Bullon, P., Wilson, M., Newman, H. (1999). Oxidative injury and inflammatory periodontal diseases: the challenge of anti-oxidants to free radicals and reactive oxygen species. Critical Reviews in Oral Biology and Medicine, 10: 458-476.

Calvin, H. I., Cooper, G. W., Wallace, E. (1981). Evidence that selenium in rat sperm is associated with a cystine rich structural protein of the mitochondrial capsule. Gamete Research, 4: 139.

Che Man, Y. B., Marina, A. M. (2006). Medium chain triacylglycerol. In F. Shaidi (ed.), Neutraceutical and specialty lipids and their co-products (pg 27-56). Boca Raton: Taylor and Francis Group.

Chiao, Y. B., Johnston, D. E., Gavaler, S. J., Van Thiel, D. H. (2008). Efect of chronic feeding on testicular content of enzymes required for testosteronogenesis. Alcoholism: Clinical and Experimental Research, 5(2): 230-236.

Dayrit, C. S. (2000). Coconut oil in health and disease: Its monolaurin potential as cure for HIV / AIDS. XXXVII Cocotech meeting, Chennai, India.

Dayrit, C. S. (2003). Cococnut oil: Atherogenic or Not? (What therefore causes Atherosclerosis?), Philippine Journal of Cardiology, 31(3): 97-104.

De Lourdes, A. M., Molina, V., Más, R., Carbajal, D., Marrero, D., Gonzalez, V., Rodriguez, E. (2007). Effects of coconut oil on testosterone-induced prostatic hyperplasia in Sprague-Dawley rats. The Journal of Pharmacy and Pharmacology, 59(7): 995-999.

Dey, A., Cederbaum, A. I. (2006). Alcohol and oxidative liver injury. Hepatology, 43: S63-S74.

Dinkova-kostova, H. and Talalay, P. (1999). Relation of structure of curcumin analogs to their potencies as inducers of phase-2 detoxification enzymes. Carcinogenesis, 20: 911-914.

El-Ashmawy, I. M., Saleh, A., Salama, O. M. (2007). Effects of marjoram volatile oil and grape seed extract on ethanol toxicity in male rats. Basic and Clinical Pharmacology and Toxicology, 101(5): 328-332.

Ellingboe, J., Varanelli, C. C. (1979). Ethanol inhibits TT biosynthesis by direct action on Leydig cells. Research Communications in Chemical Pathology and Pharmacology, 24(1): 87-102.

Emanuel, M. A., and Emanuel, N. V. (2001). Alcohol and the male reproductive system. Alcohol Research and Health, 25(4): 282-287. 
Emanuele, M., A. and Emanuele, N., V. (1998). Alcohol effects on male reproduction. Alcohol Health and Research World, 22(3): 195-201.

Emanuele, N. V., Lapagli, N., Steiner, J., Colantoni, A., Van Thiel, D. H., Emanuele, M. A. (2001). Peripupertal paternal EtOH exposure. Endocrine, 14(2): 213-219.

Frias, J., Rodriguez, R., Torres, J. M., Ruiz, E., Ortega, E. (2000). Effects of acute alcohol intoxication on pituitary gonadal axis hormones, pituitary adrenal axis hormones, beta-endorphin and prolactin in human adolescents of both sexes. Life Sciences, 67: 10811086.

Ghazali, H. M., Tan, A., Abdulkarim, S. M., Dzulkifly, M. H. (2009). Oxidative stability of virgin coconut oil compared with RBD palm olein in deep-fat frying of fish crackers. Journal of Food and Environment, 7(3-4): 23-27.

Ghosh, P., Liu, Q. H., Lakshman, M. R. (1995). Long-term ethanol exposure impairs glycosylation of both $\mathrm{N}$ - and $O$-glycosylated proteins in rat liver. Metabolism 44: 890-898.

Hurtado de Catalfo, G. E., de Alaniz, M. S., Marra, C. A. (2008). Dietary lipids modify redox homeostasis and steroidogenic status in rat testis. Nutrition, 24(7-8): 717-726.

Hurtado de Catalfo, G. E., de Alaniz, M. S., Marra, C. A. (2009). Influence of commercial dietary oils on lipid composition and TT production in interstitial cells isolated from rat testis. Lipids, 44(4): 34-357.

Iturriaga, H., Valladres, L., Hirsch, S., Devoto, E., Perez, C., Bunout, D. L., Lioi, X., Petermann, M. (1995). Effects of abstinence on sex hormone profile in alcoholic patients without liver failure. Journal of Endocrinological Investigation, 18(8): 638-644.

Larkin, J. M., Oswald, B., McNiven, M. A. (1996). Ethanolinduced retention of nascent proteins in rat hepatocytes is accompanied by altered distribution of the small GTP-binding protein rab2, Journal of Clinical Investigation, 98: 2146-2157.

Little, P. J., Adams, M. L., Cicero, T. J. (1992). Effect of alcohol on the hypothalamic pituitary gonadal axis in the developing male rat. Journal of Pharmacology and Experimental Therapeutics, 263: 1056-1061.

Lu, Y., Cederbaum, A. I. (2008). CYP2E1 and oxidative liver injury by alcohol. Free Radical Biology and Medicine, 44: 723-738.

Maneesh, M., Dutta, S., Chakrabarti, A., Vasuderan, D. M. (2006). Alcohol abuse-duration dependent decrease in plasma TT and antioxidants in males. Indian Journal of Physiology and Pharmacology, 50(3): 291-296.
Mendelson, J. H., Mello, N. K., Cristofano, P., Ellingboe, J., Skupny, A., Palmieri, S. L., Benedikt, R., Schiff, I. (1987). Alcohol effects on naloxone-stimulated LH, prolactin and estradiol in women. Journal of Studies in Alcohol, 48: 287-294.

Mendelson, J. H., Mello, N. K., Ellingboe, J. (1981). Acute alcohol intake and pituitary gonadal hormones in normal human females. Journal of Pharmacology and Experimental Therapeutics, 218: 23-26.

Nanji, A. A., Sadrzadeh, S. M., Yang, E. K., Fogt, F., Maydani, M., Dannenberg, A. J. (1995). Dietary saturated fatty acids: a novel treatment for alcoholic liver disease. Gastroenterology, 109: 547-554.

Nevin, K. G., Rajamohan, T. (2004). Beneficial effects of virgin coconut oil on lipid parameters and in vitro LDL oxidation. Clinical Biochemistry, 37(9): 830-835.

Nevin, K. G., Rajamohan, T. (2006). Virgin coconut oil supplemented diet increases the antioxidant status in rats. Food Chemistry, 99(2): 260-266.

Niehaus, W. G., Samuelsson, B. (1968). Formation of malondialdehyde from phospholipid arachidonate during microsomal lipid peroxidation. European Journal of Biochemistry, 6: 126-130.

Nour, A. H., Mohammed, F. S., Yunus, R. M., Arman, A. (2009). Demulsification of virgin coconut oil by centrifugation method: A feasibility study. International Journal of Chemical Technology, 1(2): 59-64.

Novick, P., Zerial, M. (1997). The diversity of Rab proteins in vesicle transport. Current Opinion in Cell Biology, 9: 496-504.

Onsaard, E., Vittayanont, M., Srigam, S., McClements, D. J. (2005). Properties and stability of oil-in-water emulsions stabilized by coconut skim milk proteins. Journal of Agriculture and Food Chemistry, 53: 57475753.

Polavarapu, R., Spitz, D. R., Sim, J. E., Follansbee, M.H., Oberley, L. W., Rahemtulla, A. (1998). Increased lipid peroxidation and impaired antioxidant enzyme function is associated with pathological liver injury in experimental alcoholic liver disease in rats fed diets high in corn oil and fish oil. Hepatology, 27: 13171323.

Ramos, S., Alia, M., Bravo, L., Goya, L. (2005). Comparative effects of food-derived polyphenols on the viability and apoptosis of a human hepatoma cell line (HepG), Journal of Agricultural and Food Chemistry, 53: 1271-1280. 
Ren, J. C., Zhu, Q., Lapaglia, N., Emanuele, N. V., Emanuele, M. A. (2005). Ethanol-induced alterations in Rab proteins: possible implications for pituitary dysfunction. Alcohol, 35 (2): 103-112.

Reynolds, J. E. F., (ed.,), (1982). Martindale: The ExtraPharmacopoeia $\left(28^{\text {th }}\right.$ ed). The Pharmaceutical Press, London, pp 695-698.

Ruusa, J., Bergman, B., Sundell, M. L. (1997). Sex hormones during alcohol withdrawal: a longitudinal study of 29 male alcoholics during detoxification. Alcohol and Alcoholism, 32(5): 591-597.

Salonen, I., Huhtaniemi, I. (1990). Effects of chronic ethanol diet on pituitary-testicular function of the rat, Biology of Reproduction, 42: 55-62.

Schroeter, H., Williams, R. J., Martin, R., Iversen, L., Rice E. (2000). Phenolic antioxidants attenuate neuronal cell death following uptake of oxidised low density lipoprotein. Free Radical Biology and Medicine, 29: 1222-1233.

Segev, N. (2001). Ypt/rab gtpases: regulators of protein trafficking. Science Signalling: Signal Transduction Knowledge Environment, 2001(100): re11.

Serbinova, E. A., Kagan, V., Han, D., Packer, L. (1991). Free radical recycling and intramembrane mobility inthe antioxidant properties of alpha-tocopherol and alpha-tocotrienol. Free Radical Biology and Medicine, 10(5): 263-275.

Serbinova, E. A., Packer, L. (1994). Antioxidant properties of alpha-tocopherol and alpha-tocotrienol. Methods in Enzymology, 234: 354-366.

Soudamini, K. K., Unnikrishnan, M. C., Soni, K. B., Kuttan, R. (1992). Inhibition of lipid peroxidation and cholesterol levels in mice by curcumin. Indian Journal of Physiology and Pharmacology, 36: 239-243.

Takai, Y., Sasaki, T., Matozaki, T. (2001). Small GTPbinding proteins. Physiological Reviews, 81: 153-208.

Tisdale, E. J., Bourne, J. R., Khosravi-Far, R., Der, C. J., Balch, W. E. (1992). GTP-binding mutants of rab1 and rab2 are potent inhibitors of vesicular transport from the endoplasmic reticulum to the Golgi complex. Journal of Cell Biology, 119: 749-761.

Torok, N., Marks, D., Hsiao, K., Oswald, B. J., McNiven, M. A. (1997). Vesicle movement in rat hepatocytes is reduced by ethanol exposure: alterations in microtubule-based motor enzymes. Gastroenterology, 113: $1938-1948$.

Unnikrishnan, M. K., and Rao, M. N. A. (1992). Curcumin inhibits nitrite induced methemoglobin formation. The FEBS Journal, 301: 195-196.

Välimäki, M. J., Härkönen, M., Eriksson, C. J., Ylikahri, R. $H$. (1984). Sex hormones and adrenocortical steroids in men acutely intoxicated with ethanol. Alcohol, 1(1): 89-93.

Van Thiel, D. H. (1983). Ethanol: Its adverse effects upon the hypothalamus pituitary gonadal axis. Journal of Laboratory and Clinical Medicine, 101(1): 21-33.

Van Thiel, D. H., Lester, R. (1979). The effect of chronic alcohol abuse on sexual function. Clinical Endocrinology and Metabolism, 8: 499-510.

Venkat, K. K., Arora, M. M., Singh, P., Desai, M., Khatkhatay, I. (2009). Effect of alcohol consumption on bone mineral density and hormonal parameters in physically active male soldiers. Bone, 45(3): 449-454. 